\title{
Aspirin use and chronic diseases: a cohort study of the elderly
}

\author{
Annlia Paganini-Hill, Ann Chao, Ronald K Ross, Brian E Henderson
}

\begin{abstract}
Objective-To evaluate the associations between the use of aspirin and the incidences of cardiovascular diseases, cancers, and other chronic diseases.

Design-Postal questionnaire survey to elicit details of aspirin use.

Setting-Californian retirement community.

Subjects-All 22781 residents of the community (white, affluent, and well educated) were sent a questionnaire that included questions on medical history and the use of drugs such as analgesics, laxatives, and vitamin supplements. In all $61 \%$ responded (13987, 8881 women and 5106 men; median age 73). They formed the cohort that was followed up for $6^{1 / 2}$ years using discharge summaries from three hospitals serving the area and death certificates from the health department. Only 13 respondents were lost to follow up but seemed not to have died.
\end{abstract}

Main outcome measures-Incidences of cardiovascular diseases, cancers, gastrointestinal bleeding, ulcers, and cataracts were compared in participants who did and did not take aspirin daily.

Results-Age adjusted incidences were computed with an internal standard and five age groups. By 1 January 1988 there had been 25 incident cases of kidney cancer among all participants; 341 incident cases of stroke, 253 of acute myocardial infarction, 220 of ischaemic heart disease, and 317 of other heart disease were reported among respondents without a reported history of angina, myocardial infarction, or stroke. The incidence of kidney cancer was raised among those who took aspirin daily compared with those who did not take it, although the increase was significant only in men (relative risks $=6 \cdot 3,95 \%$ confidence interval $2 \cdot 2$ to 17 , for men and $2 \cdot 1,0.53$ to 8.5 , for women). Those who took aspirin daily showed no increased risk of any other cancer, except colon cancer for both sexes combined (relative risk $=1 \cdot 5,1 \cdot 1$ to $2 \cdot 2$ ). The risk of acute myocardial infarction was reduced slightly among regular users of aspirin in men but not women. The risk of ischaemic heart disease was almost doubled in those who took aspirin daily compared with non-users (relative risks $=1 \cdot 9,1 \cdot 1$ to $3 \cdot 1$, for men and $1 \cdot 7,1 \cdot 1$ to $2 \cdot 7$, for women). Small, non-significant increased risks of stroke were observed in both sexes.

Conclusion-The daily use of aspirin increased the risk of kidney cancer and ischaemic heart disease.

\section{Introduction}

In the United States vascular diseases account for about $1 \cdot 2$ million deaths, or half of all deaths each year. Recently, the results of a large clinical trial showing that regular use of aspirin may prevent myocardial infarction have received widespread publicity.' Given the preliminary nature of this published report, the limitation of the study to men, some evidence of internal inconsistency of the results, and the contradictory findings of other trials, ${ }^{2}$ this relation cannot yet be considered secure.

As part of a prospective study on lifestyle practices and disease prevention in a retirement community in southern California, we assessed the association between regular use of analgesics containing aspirin and the incidence of several chronic diseases, including cardiovascular diseases and cancer.

\section{Methods}

In June 1981 a detailed health questionnaire was sent to all residents of Leisure World, Laguna Hills, a retirement community near Los Angeles, California. New residents who moved into the community after this date were sent the questionnaire in June 1982, June 1983, and October 1985. Residents of this community are almost always white, moderately affluent, and well educated, and about two thirds are women.

The health questionnaire requested information on previous medical diagnoses, including angina, acute myocardial infarction, hypertension, rheumatoid arthritis, and diabetes; height and weight; the use of drugs, including analgesics, laxatives, and vitamin supplements; the use of cigarettes and alcohol; exercise habits; dietary intake of certain foods; and for women menstrual and reproductive events, including use of oestrogen replacement treatment. The use of analgesics was ascertained from the questions: "Which of the following best describes your use of nonprescription pain medication? Several times a day, daily, weekly, monthly, less often or never" and "When you take non-prescription pain medication, what is the brand (for example, Empirin, Anacin, Bayer Aspirin) you usually take?"

The cohort was followed up for all hospital admissions to three hospitals serving the area $(85 \%$ of these occur at one hospital immediately adjacent to the community) and for deaths with the death certificate records of the local health department. Death certificates were also obtained for those who had died and been identified by the community business office, from the obituary column of the local newspaper, and from information provided by relatives and friends. In addition, we conducted two postings of follow up questionnaires to the cohort in 1983 and 1985. To date only 13 members of the cohort have been lost to follow up; search of the National Death Index (a computerised register of death record information maintained by the National Center for Health Statistics) did not show that these people had died.

The members of the cohort were followed up to the time of the event of interest (admission to hospital) or death or to 1 January 1988, whichever came first. Age 
adjusted relative risks using five age groups $(<75$, $75-79,80-84,85-89, \geqslant 90)$ and $p$ values were obtained with a regression method that assumed that the development of cancer or chronic disease could be regarded as a Poisson process with a constant hazard rate for a given person. ${ }^{23}$ The generalised linear interactive modelling (GLIM) software package program was used to make these calculations. ${ }^{4}$ All reported $\mathrm{p}$ values are two sided.

\section{Results}

The residents' median age was 73 . After three postings 13987 residents (61\% of the 22781 residents) returned questionnaires; 8881 of the respondents were women. The distribution of sex was comparable in respondents and non-respondents, but the nonrespondents were slightly older; overall mortality was greater in non-respondents in the first few years of follow up and then became identical with that in the respondents.

By 1 January 1988 the 8881 women and 5106 men in the cohort had contributed over 42000 and 25000 person years of follow up, respectively. The incidence of kidney cancer was increased among daily users of aspirin in both men and women, although the result was significant only in the men (table I). This increase was more evident for renal cell carcinomas (sex and age adjusted relative risk $=6 \cdot 3,95 \%$ confidence interval $2 \cdot 0$ to $20, p<0.01$, for daily aspirin users compared with non-users) than for transitional cell cancers (relative risk $=2 \cdot 2,0 \cdot 65$ to $7 \cdot 6, p=0 \cdot 20$ ).

Colon cancer showed some increased risk with the use of aspirin in both sexes (table I). The result was significant in both sexes combined (sex and age adjusted relative risk $=1 \cdot 5,1 \cdot 1$ to $2 \cdot 2, \mathrm{p}<0.05$ for daily aspirin users compared with non-users). The increased risk was not restricted to a particular segment of the colon (data not shown). No other strong or significant cancer associations were apparent between the regular use of aspirin and the development of any other cancer.

TABLE I-Numbers of cases and age adjusted relative risks for incidence of cancer by sex and use of analgesics containing aspirin

\begin{tabular}{|c|c|c|c|c|c|c|c|c|c|c|}
\hline \multirow[b]{2}{*}{ Aspirin use } & \multicolumn{2}{|c|}{ Colon } & \multicolumn{2}{|c|}{ Lung } & \multicolumn{2}{|c|}{ Bladder } & \multicolumn{2}{|c|}{ Kidney } & \multicolumn{2}{|c|}{ Prostate or breast } \\
\hline & $\begin{array}{l}\text { No of } \\
\text { cases }\end{array}$ & $\begin{array}{c}\text { Relative } \\
\text { risk }\end{array}$ & $\begin{array}{l}\text { No of } \\
\text { cases }\end{array}$ & $\begin{array}{c}\text { Relative } \\
\text { risk }\end{array}$ & $\begin{array}{l}\text { No of } \\
\text { cases }\end{array}$ & $\begin{array}{l}\text { Relative } \\
\text { risk }\end{array}$ & $\begin{array}{l}\text { No of } \\
\text { cases }\end{array}$ & $\begin{array}{c}\text { Relative } \\
\text { risk }\end{array}$ & $\begin{array}{l}\text { No of } \\
\text { cases }\end{array}$ & $\begin{array}{c}\text { Relative } \\
\text { risk }\end{array}$ \\
\hline \multicolumn{11}{|l|}{ Men: } \\
\hline None $(n=3490)$ & 47 & $1 \cdot 00$ & 46 & 1.00 & 55 & $1 \cdot 00$ & 6 & 1.00 & 106 & $1 \cdot 00$ \\
\hline$<$ Daily $(\mathrm{n}=685)$ & 13 & 1.39 & 8 & $0 \cdot 87$ & 4 & 0.37 & & & 18 & $0 \cdot 90$ \\
\hline Daily $(n=876)$ & 19 & 1.67 & 15 & 1.35 & 15 & $1 \cdot 12$ & 9 & $6 \cdot 28^{\star}$ & 25 & 0.95 \\
\hline \multicolumn{11}{|l|}{ Women: } \\
\hline None $(n=6021)$ & 66 & $1 \cdot 00$ & 32 & 1.00 & 14 & $1 \cdot 00$ & 6 & $1 \cdot 00^{\star}$ & 146 & 1.00 \\
\hline$<$ Daily $(n=1417)$ & 15 & 0.95 & 8 & 1.00 & 5 & 1.56 & 1 & 0.72 & 33 & 0.95 \\
\hline Daily $(n=1380)$ & 21 & $1 \cdot 41$ & 2 & $0 \cdot 29$ & 3 & $0 \cdot 89$ & 3 & $2 \cdot 11$ & 35 & 0.96 \\
\hline
\end{tabular}

${ }^{\star} \mathrm{p}<0 \cdot 05$.

TABLE II - Numbers of cases and age adjusted relative risks for incidence of cardiovascular diseases (excluding people with reported history of angina, acute myocardial infarction, and stroke) by sex and use of analgesics containing aspirin

\begin{tabular}{|c|c|c|c|c|c|c|c|c|c|c|}
\hline \multirow[b]{2}{*}{ Aspirin use } & \multicolumn{2}{|c|}{$\begin{array}{c}\text { Total (ICD 390- } \\
438)\end{array}$} & \multicolumn{2}{|c|}{$\begin{array}{l}\text { Stroke (ICD 430, } \\
431,434,436)\end{array}$} & \multicolumn{2}{|c|}{$\begin{array}{l}\text { Acute myocardial } \\
\text { infarction (ICD } \\
410)\end{array}$} & \multicolumn{2}{|c|}{$\begin{array}{l}\text { Ischaemic heart } \\
\text { disease (ICD } 411 \text { - } \\
\text { 414) }\end{array}$} & \multicolumn{2}{|c|}{$\begin{array}{c}\text { Other heart } \\
\text { disease (ICD 402, } \\
424,425,428, \\
429,440,441)\end{array}$} \\
\hline & $\begin{array}{l}\text { No of } \\
\text { cases }\end{array}$ & $\begin{array}{l}\text { Relative } \\
\text { risk }\end{array}$ & $\begin{array}{l}\text { No of } \\
\text { cases }\end{array}$ & $\begin{array}{l}\text { Relative } \\
\text { risk }\end{array}$ & $\begin{array}{l}\text { No of } \\
\text { cases }\end{array}$ & $\begin{array}{l}\text { Relative } \\
\text { risk }\end{array}$ & $\begin{array}{l}\text { No of } \\
\text { cases }\end{array}$ & $\begin{array}{l}\text { Relative } \\
\text { risk }\end{array}$ & $\begin{array}{l}\text { No of } \\
\text { cases }\end{array}$ & $\begin{array}{l}\text { Relative } \\
\text { risk }\end{array}$ \\
\hline \multicolumn{11}{|l|}{ Men: } \\
\hline None $(n=2587)$ & 406 & 1.00 & 101 & $1 \cdot 00$ & 98 & 1.00 & 54 & $1 \cdot 00$ & 87 & $1 \cdot 00$ \\
\hline$<$ Daily $(n=529)$ & 80 & 1.02 & 16 & 0.87 & 13 & 0.64 & 17 & 1.51 & 21 & $1 \cdot 25$ \\
\hline Daily $(n=516)$ & 113 & $1 \cdot 46^{\star}$ & 26 & 1.22 & 14 & 0.73 & 19 & $1 \cdot 86^{\star}$ & 29 & $1 \cdot 64$ \\
\hline \multicolumn{11}{|l|}{ Women: } \\
\hline None $(n=5169)$ & 568 & 1.00 & 135 & $1 \cdot 00$ & 86 & $1 \cdot 00$ & 77 & $1 \cdot 00$ & 124 & $1 \cdot 00$ \\
\hline$<$ Daily $(\mathrm{n}=1207)$ & 122 & 0.97 & 26 & 0.88 & 22 & $1 \cdot 16$ & 25 & $1 \cdot 45$ & 23 & $0 \cdot 85$ \\
\hline Daily $(n=1063)$ & 166 & $1 \cdot 39^{\star}$ & 37 & $1 \cdot 27$ & 20 & $1 \cdot 06$ & 28 & $1 \cdot 72^{\star}$ & 33 & $1 \cdot 21$ \\
\hline
\end{tabular}

${ }^{\star} \mathrm{p}<0.05$.

ICD = International Classification of Diseases (ninth revision).
For analyses of the relation between cardiovascular disease and use of aspirin we excluded 1432 men and 1394 women who had reported a history of angina, myocardial infarction, or stroke in the initial survey (table II). The incidence of ischaemic heart disease was raised among daily users of aspirin compared with nonusers among both men and women (relative risk $=1 \cdot 9$, $1 \cdot 1$ to $3 \cdot 1, \mathrm{p}<0.05$ and $1 \cdot 7,1 \cdot 1$ to $2 \cdot 7, \mathrm{p}<0.05$, respectively). Except for "other heart disease" (including various diseases, the numerically most important of which was heart failure) in men, the use of aspirin was not significantly related to any other vascular disease examined. A $20-30 \%$ increased risk of stroke was, however, seen in men and women who took aspirin daily, but neither of these results was significant (sex and age adjusted relative risk $=1 \cdot 3,0 \cdot 96$ to $1 \cdot 7, p=0 \cdot 10$ for daily aspirin users compared with non-users). For all cardiovascular disease combined the risk was raised among daily users of aspirin compared with non-users among both men and women (relative risks $=1 \cdot 5,1 \cdot 2$ to $1 \cdot 8, \mathrm{p}<0.05$ and $1 \cdot 4,1 \cdot 2$ to $1 \cdot 7, \mathrm{p}<0.05$, respectively).

Other chronic diseases examined because of previous evidence of a possible association with regular use of aspirin included gastrointestinal bleeding, gastric ulcers, and cataracts (table III). Among women, those who used aspirin less than daily showed a significant reduction in risk for ulcers (relative risk= $0 \cdot 3,0 \cdot 14$ to $0 \cdot 74, \mathrm{p}<0.05$ ), but there was no evidence of a dose-response effect. No other result was significant or substantially different from unity.

TABLE III-Numbers of cases and age adjusted relative risks for incidence of other diseases by sex and use of analgesics containing aspirin

\begin{tabular}{|c|c|c|c|c|c|c|}
\hline \multirow[b]{2}{*}{ Aspirin use } & \multicolumn{2}{|c|}{$\begin{array}{l}\text { Gastrointestinal } \\
\text { bleeding }\end{array}$} & \multicolumn{2}{|c|}{ Ulcers } & \multicolumn{2}{|c|}{ Cataracts } \\
\hline & $\begin{array}{l}\text { No of } \\
\text { cases }\end{array}$ & $\begin{array}{l}\text { Relative } \\
\text { risk }\end{array}$ & $\begin{array}{l}\text { No of } \\
\text { cases }\end{array}$ & $\begin{array}{l}\text { Relative } \\
\text { risk }\end{array}$ & $\begin{array}{l}\text { No of } \\
\text { cases }\end{array}$ & $\begin{array}{c}\text { Relative } \\
\text { risk }\end{array}$ \\
\hline \multicolumn{7}{|l|}{ Men: } \\
\hline None $(n=3490)$ & 37 & $1 \cdot 00$ & 53 & 1.00 & 130 & $1 \cdot 00$ \\
\hline$<$ Daily $(\mathrm{n}=685)$ & 5 & 0.73 & 13 & $1 \cdot 26$ & 21 & 0.83 \\
\hline Daily $(n=876)$ & 13 & $1 \cdot 38$ & 13 & $1 \cdot 00$ & 39 & $1 \cdot 21$ \\
\hline \multicolumn{7}{|l|}{ Women: } \\
\hline None $(n=6021)$ & 37 & $1 \cdot 00$ & 81 & $1 \cdot 00$ & 343 & 1.00 \\
\hline$<$ Daily $(n=1417)$ & 8 & 0.95 & 6 & $0.32^{\star}$ & 63 & $0 \cdot 80$ \\
\hline Daily $(n=1380)$ & 12 & $1 \cdot 29$ & 5 & 0.76 & 99 & $1 \cdot 21$ \\
\hline
\end{tabular}

${ }^{\star} \mathrm{p}<0 \cdot 05$.

\section{Discussion}

Five case-control studies of cancer of the renal pelvis $^{5.9}$ and two of renal cell carcinoma ${ }^{510}$ have evaluated the association with use of analgesics, and we have reviewed the subject. " Two studies conducted by McCredie et al in New South Wales suggested a strong association between "regular" use of analgesics and cancer of the renal pelvis in both sexes. ${ }^{67}$ The second study suggested that in women this strong association was limited mainly to compounds containing phenacetin. ${ }^{7}$ In a study in Minnesota McLaughlin et al found $3 \cdot 9$-fold and $3 \cdot 7$-fold excess risks of cancer of the renal pelvis in men and women, respectively, who were regular long term ( $>36$ months) users of drugs containing phenacetin or paracetamol compared with nonusers. ${ }^{8}$ Neither result, however, was significant. Our case-control study of cancer of the renal pelvis and ureter suggested that heavy use of analgesics obtained over the counter without a prescription is associated with an increased risk and that the increased risk extends across formulations containing all the main active ingredients of preparations currently used in the United States, including aspirin. ${ }^{9}$ The data on renal cell carcinoma are scanty and inconclusive. ${ }^{510}$ Our current results are compatible with these published findings for cancer of the renal pelvis and suggest that 
an even stronger association may exist between the regular use of aspirin and the development of renal cell carcinoma.

We are not aware of previous reports of an association between cancer of the colon and aspirin intake. Aspirin causes gastric irritation. In sufficiently high doses and combined with interference in absorption by foodstuffs in the intestinal lumen or through other mechanisms, aspirin might similarly affect the large bowel. Such irritation may lead to increased activity of mucosal stem cells and to an increased risk of cancer.

Evidence that regular administration of aspirin may be beneficial to patients with established coronary heart disease comes from several sources ${ }^{12-15}$ and has been recently reviewed by the Antiplatelet Trialists' Collaboration. ${ }^{16}$ Overall, in 25 completed randomised trials of antiplatelet treatment (including aspirin) in patients with a history of transient ischaemic attack, occlusive stroke, unstable angina, or myocardial infarction allocation to antiplatelet treatment reduced mortality from vascular diseases by $15 \%$ but had no apparent effect on mortality from non-vascular diseases. There was no significant difference among the effects of the different types of antiplatelet treatment tested (300-325 mg aspirin daily, higher aspirin doses, sulphinpyrazone, or high dose aspirin with dipyridamole) or between the effects in patients with histories of cerebral or cardiac vascular diseases.

There have been two randomised trials of aspirin for the primary prevention of cardiovascular disease. The physicians' health study is a double blind, placebo controlled trial of 22071 male doctors in the United States between the ages of 40 and 84 . A primary aim of the study is to determine whether $325 \mathrm{mg}$ aspirin taken every other day reduces mortality from and incidence of vascular disease. ${ }^{17}$ After an average of 4.8 years of follow up there was no difference between the aspirin and placebo groups in total cardiovascular deaths (relative risk $=0.99$ ). The overall mortality from cardiovascular disease was extraordinarily and inexplicably low: 733 deaths expected $v 88$ observed. The patterns of risk of vascular disease associated with the regular use of aspirin in that study are strikingly similar to the patterns of incidence in men in our study. The physicians' health study observed a $47 \%$ reduction in the overall risk of fatal and non-fatal myocardial infarction (relative risk $=0.53, \mathrm{p}<0.00001$ ); we observed a non-significant reduction in risk of myocardial infarction of $36 \%$ and $27 \%$ among those who took aspirin daily and those who took it less often, respectively. For stroke there was a non-significant increase of $15 \%$ among those receiving aspirin in the physicians' health study (relative risk $=1 \cdot 15, \mathrm{p}=0.41$ ); our results indicate a $22 \%$ increase in risk associated with daily aspirin use. For deaths from ischaemic heart disease (data on morbidity were not reported) the relative risk was increased only slightly in the physicians' health study (relative risk $=1 \cdot 08, \mathrm{p}=0 \cdot 81$ ) compared with a substantially higher and significant increase observed in our study (relative risk $=1 \cdot 86$ ). We presume, however, that the category "sudden death" in the physicians' health study (relative risk $=1 \cdot 49$ ) includes subjects with underlying ischaemic heart disease. The relative risk for "other" cardiovascular disease deaths (relative risk $=1 \cdot 79$ ) was also quite similar to that in our study (relative risk $=1.64$ ).

The only other data on the role of aspirin in the primary prevention of cardiovascular disease derive from a randomised trial of 5139 British doctors that tested $500 \mathrm{mg}$ of aspirin daily. ${ }^{18}$ In contrast with the physicians' health study the British data showed no differences in risk of fatal or non-fatal myocardial infarction between those assigned to the aspirin and the control groups. Like the physicians' health study and our study, a slight but non-significant excess of strokes was observed among those assigned to the aspirin group. No difference was observed in the mortality from all cardiovascular diseases.

Although aspirin treatment has proved benefit for those with a history of cardiovascular disease (secondary prevention), data from the two clinical trials combined with the results from our large prospective study suggest that the risk-benefit equation might balance differently for primary prevention. Though the reduction in mortality from acute myocardial infarction in the physicians' health study was significant, it was accompanied by small increases in mortality from other vascular diseases so that no overall reduction in mortality from vascular diseases was apparent. This observation is supported by data on mortality from the British study and from our data on the incidences of chronic disease. We extend these observations to show no reduction in incidence of vascular disease in women who use aspirin daily. In fact, our study found a significantly increased incidence of ischaemic heart disease in regular aspirin users of both sexes and an increased incidence of "other" heart disease, which was significant in men.

Gastrointestinal discomfort and bleeding and gastric ulcers are established hazards of aspirin use, especially in high doses. ${ }^{16}{ }^{19-22}$ In a resurvey of a sample of our cohort who took analgesics daily we found that a quarter of the 190 respondents avoided analgesics containing aspirin because of a history of ulcers or stomach problems. If such people at high risk avoid taking aspirin the risk of ulcers in aspirin users would be reduced, as observed in our study.

The use of aspirin has been reported to be protective for cataracts in studies of patients with rheumatoid arthritis, ${ }^{23}$ diabetic patients, ${ }^{24}$ and patients admitted for cataract extraction. ${ }^{25} 26$ Other studies have not, however, confirmed this effect, ${ }^{187-29}$ and we see no apparent protection in our cohort despite a substantial number of cases.

Although our data on use of analgesics are self reported, we have evidence that these data are reliable. ${ }^{30}$ In the resurvey conducted in 1988 of 190 respondents who took analgesics daily $132(69 \%)$ were still taking an analgesic every day. For these 132 the primary reasons for taking an analgesic were reported to be for arthritis $(61(46 \%))$; for prevention of heart disease, angina, and stroke and as a blood thinner (30 $(23 \%))$; and for headache $(7(5 \%))$.

This work was supported by grants CA32197 and CA17054 from the National Cancer Institute, National Institutes of Health, Bethesda, Maryland. We thank Mary Arthur and Beverly Ducey, research staff, for their help, and the residents of Leisure World, Laguna Hills, California, whose cooperation made this work possible.

1 Physicians' Health Study Research Group Preliminary report: findings from the aspirin component of the ongoing Physicians' Health Study. N Engl f Med 1988;318:262-4

2 Breslow NE, Lubin JH, Marek P, Langholz B. Multiplicative models and cohort analysis. Fournal of the American Statistical Association 1983;78:1-12. 3 Fromme EL. The analysis of rates using Poisson regression models. Biometrics 1983;39:665

4 Baker RJ, Nelder JA. The GLIM system: release 3. Oxford: Numerical Algorithms Group, 1978.

5 Armstrong B, Garrod A, Doll R. A retrospective study of renal cancer with special reference to coffee and animal protein consumption. $\mathrm{Br} \mathcal{I}$ Cancer 1976;33:127-36.

6 McCredie M, Ford JM, Taylor JS, Stewart JH. Analgesics and cancer of the renal pelvis in New South Wales. Cancer 1982;49:2617-25.

7 McCredie M, Stewart JH, Ford JM, MacLennan RA. Phenacetin-containing analgesics and cancer of the bladder or renal pelvis in women. $\mathrm{Br} \mathcal{F} \mathrm{Urol}$ 1983:55:220-4.

8 McLaughlin JK, Blot WJ, Mandel JS, Schuman LM, Mehl ES, Fraumeni JF Jr. Etiology of cancer of the renal pelvis. FNCI 1983;71:287-91.

9 Ross RK, Paganini-Hill A, Landolph J, Gerkins V, Henderson BE. Analgesics, cigarette smoking and other risk factors for cancer of the renal pelvis and ureter. Concer Res 1989;49:1045-9.

10 McLaughlin JK, Mandel JS, Blot WJ, Schuman LM, Mehl ES, Fraumeni JF Jr. A population-based case-control study of renal cell carcinoma. $7 N C I$ 1984;72:275-84

11 Paganini-Hill A, Ross RK, Henderson BE. Epidemiology of renal cancer. In: 
Skinner DG, Lieskovsy G, eds. Diagnosis and munagement of geniourinury cancer. Philadelphia: WB Saunders, 1988:32-9.

12 Boston Collaborative Drug Surveillance Group. Regular aspirin intake and acute myocardial infarction. Br Med 7 1974; i: $440-3$.

13 Elwood PC, Cochrane AL, Burr ML, et al. A randomized controlled trial of aceryl salicylic acid in the secondary prevention of mortality from myocardial infarction. Br Med f 1974; ; : 436-40.

14 Coronary Drug Project Research Group. Aspirin in coronary heart disease. f Chronic Dis 1978;29:625-42.

15 Aspirin Myocardial Infarction Study Research Group. A randomized, controlled trial of aspirin in persons recovered from myocardial infarction. JAMA 1980;243:661-9.

16 Antiplatelet Trialists' Collaboration. Secondary prevention of vascular disease by prolonged antiplatelet treatment. $\mathrm{Br}$ Med $\mathcal{F}$ 1988;296:320-31.

17 Young FE, Nightingale, Temple RA. The preliminary report of the finding of the aspirin component of the ongoing Physicians' Health Study. The FDA perspective on aspirin for the primary prevention of myocardial infarction. ҰAMA 1988;259:3158-60.

18 Peto R, Gray R, Collins R, et al. A randomised trial of the effects of prophylactic daily aspirin among male British doctors. Br Med f 1988;296: 313-6.

19 Belcon MC, Rooney PJ, Tugwell P. Aspirin and gastrointestinal haemorrhage: a methodologic assessment. I Chronic Dis 1985;38:101-11.

20 Piper DW, McIntosh JH, Aritotti DE, Fenton BH, MacLennan R. Analgesic ingestion and chronic peptic ulcer. Gastroenterology 1981;80:427-32.
21 McIntosh JH, Byth R, Piper DW. Environmental factors in aetiology of chronic gastric ulcer: a case control study of exposure variables before the first symptoms. Gut 1985;26:789-98.

22 Faulkner G, Prichard P, Somerville K, Langman MJS. Aspirin and bleeding peptic ulcers in the elderly. Br Med $\mathcal{F} 1988 ; 297: 1311-3$.

23 Cotlier $\mathrm{E}$. Aspirin and senile cataract in rheumatoid arthritis. Lancel $1981 ; i: 338-9$.

24 Cotlier E. Senile cataracts: evidence for acceleration by diabetes and deceleration by salicylate. Can 7 Ophthalmol 1981;16:113-8.

25 Van Heyningen R, Harding JJ. Do aspirin-like analgesics protect agains cataract? Lancet $1986 ; \mathrm{i}: 1111-3$.

26 Cotlier E. Rheumatoid arthritis and cataract surgery. Int Ophthalmol 1980;2 127-9.

27 Seigel D, Sperduto RD, Ferris FL III. Aspirin and cataracts. Ophthalmology 1982;89:47-8A.

28 West SK, Munoz BE, Newland HS, Emmett EA, Taylor HR. Lack of evidence for aspirin use and prevention of cataracts. Arch Ophthalmol 1987;105:1229-31.

29 Kewitz H, Nitz M, Gaus V. Aspirin and cataract. Lancet 1986;ii:689.

30 Paganini-Hill A, Ross RK. Reliability of recall of drug usage and other health related information. Am $\mathcal{F}$ Epidemiol 1982;116:114-22.

(Accepted 15 September 1989)

\title{
Perinatal transmission of HIV-I in Zambia
}

\author{
S K Hira, J Kamanga, G J Bhat, C Mwale, G Tembo, N Luo, P L Perine
}

Dermato-Venereology Department, University Teaching Hospital, Box 50001, Lusaka, Zambia S K Hira, MD, consultant J Kamanga, DCMS, clinical officer

C Mwale, DCMS, clinical officer

Department of Paediatrics, University Teaching

Hospital, Lusaka

G J Bhat, MD, senior lecturer

Department of Community Medicine, University

Teaching Hospital, Lusaka

G Tembo, MPH, lecturer

Department of Pathology/ Immunology, University

Teaching Hospital, Lusaka

N Luo, PHD, lecturer

Uniformed Services

University of the Health

Sciences, Bethesda,

Maryland, United States

$\mathrm{PL}$ Perine, MPH, professor of

tropical public health

Correspondence to:

Dr Hira.

BrMed F 1989;299:1250-2

\section{Abstract}

Objective-To determine the occurrence of vertical transmission of HIV-I from women positive for the virus and the prognosis for their babies.

Design-Women presenting in labour were tested for HIV-I. Their newborn babies were also tested. Women positive for the virus were followed up with their babies for two years.

Setting-Teaching hospital in Lusaka, Zambia.

Subjects - 1954 Women, of whom 227 were seropositive. Of 205 babies, 192 were positive for HIV-I. After birth 109 seropositive mothers and their babies and $\mathbf{4 0}$ seronegative mothers and their babies were available for follow up.

Main outcome measures-Serological examination of mothers and their babies by western blotting. Birth weight and subsequent survival of babies. Women and babies were tested over two years for signs of seroconversion and symptoms of infection with HIV, AIDS related complex, and AIDS.

Results - Of the 109 babies born to seropositive mothers and available for follow up, 18 died before 8 months, 14 with clinical AIDS. Of the 91 remaining, 23 were seropositive at 8 months. By 24 months 23 of 86 surviving babies were seropositive, and a further five infected babies had died, four were terminally ill, 17 had AIDS related complex, and two had no symptoms. The overall rate of perinatal transmission was 42 out of $109(39 \%)$. The overall mortality of infected children at 2 years was 19 out of $42(44 \%)$. Before the age of 1 year infected children had pneumonia and recurrent coughs, thereafter symptoms included failure to thrive, recurrent diarrhoea and fever, pneumonia, candidiasis, and lymphodenopathy. All babies had received live attenuated vaccines before 8 months with no adverse affects.

Conclusions - Vertical transmission from infected mothers to their babies is high in Zambia and prognosis is poor for the babies. Perinatal transmission and paediatric AIDS must be reduced, possibly by screening young women and counselling those positive for HIV-I against future pregnancy.

\section{Introduction}

HIV-I may be transmitted from an infected mother to her fetus during pregnancy or childbirth. ${ }^{14}$ Various studies estimate that about $20-50 \%$ of infants born of infected mothers are also infected. ${ }^{56}$ We studied the incidence of vertical transmission of HIV-I in Lusaka, Zambia, and the possible risks of immunising potentially infected infants with attenuated vaccines.

\section{Patients and methods}

During February to May 1987, 1954 consecutive women delivering at this hospital were entered in the study. We obtained detailed histories after getting informed consent and performed a thorough physical examination and collected $3-5 \mathrm{ml}$ venous blood. Cord blood was taken from live and stillborn infants. The serum samples of mother, baby, and, in some cases, the father were tested for antibodies to HIV-I by enzyme linked immunosorbent assay (ELISA) and western blot analysis. We attempted to trace and follow up two groups: (a) all women positive for antibody to HIV-I and their infants and (b) 40 sets of women negative for antibody to HIV-I and their infants. All seropositive women and their spouses were counselled. Repeat venous blood samples were collected from mothers and infants in both the groups at 6-8, 12, 18, and 24 months and tested for antibodies to HIV and a complete blood count was done. All children received vaccines: BCG at birth, oral polio and diphtheria, pertussis, and tetanus at 3,4 , and 5 months, and measles at 8 months.

Data were analysed by using $\chi^{2}$ tests with epidemiologic software from the Centers for Disease Control.

\section{Results}

Of 1954 women screened at delivery, $227(12 \%)$ were seropositive for HIV-I. The seropositive women were significantly younger with a mean (SD) age of 23.9 $(5.4)$ years (Student's $t$ test $p<0 \cdot 05)$. The seronegative women had a mean (SD) age of $25 \cdot 1(7 \cdot 7)$ years. Among seropositive women, $62(27 \%)$ were primigravidas and $185(82 \%)$ were married. Risk cofactors such as higher number of lifetime sexual partners (table I), single or divorced or widowed, higher educational state (table II), history of transfusion, travel abroad, and working (table III) were associated with high seroprevalence of HIV-I. Fifty two $(23 \%)$ of the seropositive women had adverse outcomes compared with $227(13 \%)$ of the seronegative women 